\title{
Partial thromboplastin time is more predictive of bleeding than anti-Xa levels in heparinized pediatric patients after cardiac surgery
}

\author{
Olubunmi O. Oladunjoye, MBBS, ${ }^{\mathrm{a}}$ Lynn A. Sleeper, ScD, ${ }^{\mathrm{b}}$ Asha G. Nair, MD, ${ }^{\mathrm{b}}$ \\ Cameron C. Trenor III, MD, ${ }^{\mathrm{c}}$ Christina VanderPluym, MD, ${ }^{\mathrm{b}}$ John N. Kheir, MD, ${ }^{\mathrm{b}}$ and \\ Sitaram M. Emani, MD
}

\section{ABSTRACT}

Objectives: Anticoagulation with unfractionated heparin (UFH) after pediatric cardiac surgery can be monitored using either activated partial thromboplastin time (aPTT) or anti-factor Xa activity (anti-Xa). However, correlation of bleeding with either of these laboratory values has not been established. We sought to determine the correlation between bleeding events and aPTT and anti-Xa in patients who undergo anticoagulation after congenital heart surgery.

Methods: We prospectively studied pediatric patients treated with UFH after cardiac surgery over an 11-month period. Bleeding events were prospectively assessed and adjudicated. The highest aPTT and corresponding anti-Xa for the 24 hours before bleeding events were collected to assess for association with bleeding. Statistical analysis was performed using generalized additive logistic regression.

Results: A total of 202 patients received UFH over 1488 patient-days. The median age at surgery was 0.4 years (interquartile range, 0.1-2.2). A total of 45 major or clinically relevant bleeding events were observed. The correlation between aPTT and anti-Xa was of moderate strength $(R=0.58 ; P<.001)$. The odds of bleeding increased significantly when aPTT exceeded 150 (odds ratio, 1.71 per 10 -second increase in aPTT, 95\% confidence interval, 1.21-2.42; $P=.003$ ). Anti-Xa was not associated with bleeding (odds ratio, 1.11 per 0.1 $\mathrm{IU} / \mathrm{mL}$ increase, 95\% confidence interval, 0.89-1.29; $P=.34$ ).

Conclusions: In heparinized pediatric patients after cardiac surgery, increased risk of bleeding is more closely associated with elevated aPTT levels than elevated anti-Xa levels. In addition to anti-Xa, monitoring of aPTT levels should be considered during titration of UFH in pediatric patients after cardiac surgery. (J Thorac Cardiovasc Surg 2018;156:332-40)

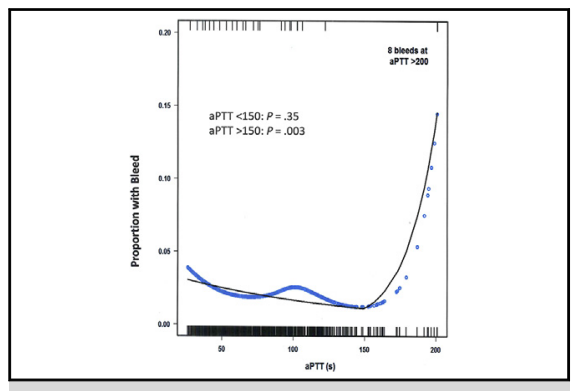

Estimated probability of major or clinically relevant nonmajor bleeding.

\section{Central Message}

An aPTT level is more strongly associated with an increased incidence of bleeding than anti-Xa level in patients after cardiac surgery.

\section{Perspective}

It is not known whether aPTT or anti Xa level is a better predictor of bleeding in pediatric patients who are being anticoagulated with unfractionated heparin after congenital heart surgery. An aPTT level $>150$ seconds correlated highly with risk of bleeding.

See Editorial Commentary page 341.
From the Departments of ${ }^{\mathrm{a}}$ Cardiovascular Surgery and ${ }^{\mathrm{b}}$ Cardiology, and ${ }^{\mathrm{c}}$ Division of Hematology/Oncology, Boston Children's Hospital, Boston, Mass.

This study was supported by funding from the Goldwin Foundation, Lincoln, Nebraska.

Read at the 97th Annual Meeting of The American Association for Thoracic Surgery, Boston, Massachusetts, April 29-May 3, 2017.

Received for publication May 1, 2017; revisions received Nov 30, 2017; accepted for publication Feb 11, 2018; available ahead of print April 27, 2018.

Address for reprints: Sitaram M. Emani, MD, Department of Cardiovascular Surgery, Boston Children's Hospital, 300 Longwood Ave, Boston, MA 02115 (E-mail: Sitaram.Emani@cardio.chboston.org).

$0022-5223 / \$ 36.00$

Copyright (c) 2018 by The American Association for Thoracic Surgery

https://doi.org/10.1016/j.jtcvs.2018.02.101
Pediatric patients who undergo certain types of cardiac surgery are at increased risk for thrombosis and are frequently treated with unfractionated heparin (UFH) early

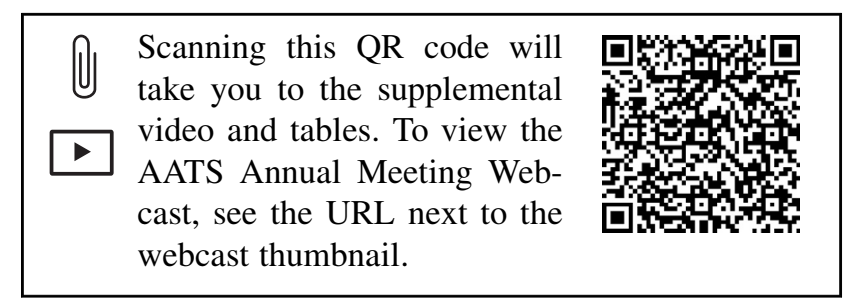




$$
\begin{aligned}
& \text { Abbreviations and Acronyms } \\
& \begin{aligned}
\text { Anti-Xa } & =\text { anti-factor Xa activity } \\
\text { aPTT } & =\text { activated partial thromboplastin time } \\
\text { ATIII } & =\text { antithrombin III } \\
\text { CI } & =\text { confidence interval } \\
\text { CICU } & =\text { cardiac intensive care unit } \\
\text { IQR } & =\text { interquartile range } \\
\text { OR } & =\text { odds ratio } \\
\text { PD } & =\text { patient-days } \\
\text { UFH } & =\text { unfractionated heparin }
\end{aligned}
\end{aligned}
$$

after surgery to prevent or treat thromboembolic events. However, bleeding represents a major complication of anticoagulation in this early postoperative period, with reported incidence rates ranging from $1.5 \%$ to $24 \% .^{1-5}$ Balancing the timing and intensity of anticoagulation with postoperative bleeding risk is conceptually ideal to minimize the risk of bleeding as well as thrombosis.

In pediatrics, monitoring of UFH dosing is challenging, because of the volume of blood required and variability in activated partial thromboplastin time (aPTT) between patients. Furthermore, existing assays for UFH monitoring are discrepant and poorly predict bleeding or thrombosis. ${ }^{6}$ The 2 primary methods used for monitoring UFH are aPTT and anti-factor Xa activity (anti-Xa). The aPTT is a functional assay that measures the rate of clot formation after intrinsic pathway activation by an activator such as silica or kaolin. The aPTT test is confounded by hepatic coagulopathy, developmental hemostasis, factor VIII elevation, lupus anticoagulant, and other coagulopathies independent of UFH. The anti-Xa test assesses the biochemical activity of heparin by measuring the cleavage of a substrate by factor Xa. In the presence of heparin, heparin-bound antithrombin complex inhibits activity of factor Xa, leading to decreased substrate cleavage. Anti-Xa is underestimated in the setting of circulating antithrombin III (ATIII) deficiency. ${ }^{7}$

Before 2000, aPTT was primarily used to monitor and titrate heparin dosing, but subsequently recommendations were made in the literature to adjust dosing to achieve anti-Xa between 0.3 and $0.8 \mathrm{IU} / \mathrm{mL}^{.}{ }^{8}$ However, there is generally poor correlation between anti-Xa and aPTT, which varies with age. ${ }^{9}$ Correlation is particularly poor in younger children (younger than 1 year) who have relatively lower circulating levels of ATIII. The use of anti-Xa to monitor UFH dosing might result in higher doses of heparin administration and elevated aPTT levels, whereas the use of aPTT might result in dose reductions and subtherapeutic anti-Xa. ${ }^{10,11}$ Although several groups have described a discrepancy between aPTT and anti-Xa, no studies have shown superiority of one method over the other in the prediction of clinical outcomes of bleeding or thrombosis prophylaxis in patients who undergo cardiac surgery. The primary objective of this study was to determine the association between laboratory markers (aPTT and anti-Xa) and bleeding as well as to determine the correlation between these 2 laboratory markers.

\section{METHODS}

This was a single-center prospective analysis of all patients who underwent cardiac surgery at Boston Children's Hospital between August 2015 and July 2016 who were treated with therapeutic anticoagulation with UFH. Patients were prospectively followed from admission until discharge from the cardiac intensive care unit (CICU).

In this study, the anticoagulation approach was decided upon by the attending surgeon and intensivists. Patients at high risk for thrombosis received therapeutic heparin. These included certain procedures-prosthetic valve replacement of any position in a young child (except pulmonary valve), extensive intracardiac baffling (atrial switch, Fontan procedure), stage I palliation, and Blalock-Taussig shunts. Patients with a recent or remote history of thrombosis also underwent anticoagulation.

The aPTT and anti-Xa level measurements were part of the routine institutional practice, and this study was initiated as a quality improvement protocol, although approval was obtained from the Boston Children's hospital institutional review board to review and report the results. Patients received monitoring via blood testing of anti-Xa as well as aPTT, with prospective monitoring of clinical outcomes. During most of this study, clinicians used anti-Xa levels to titrate UFH dosing according to guidelines in the literature. During the latter part of the study period, clinicians began to use aPTT to limit the dose of heparin according to the protocol outlined in Figure 1.

Clinical data, including aPTT and anti-Xa laboratory values, anticoagulation strategy, and all doses of UFH were collected daily. The aPTT was run in the core lab on PTT Automate 5 with silica activator and anti-Xa activity was run in the core lab without the addition of exogenous ATIII on Stago STA-R Evolution (Diagnostica Stago Inc, Parsippany, NJ). Simultaneous measurement of aPTT and anti-Xa was performed in all patients as a part of the anticoagulation monitoring panel, and titration of UFH took place according to anti-Xa and aPTT levels. Monitoring assay samples were mostly drawn from nonheparinized lines to avoid sample contamination. ${ }^{12}$ Staff typically identified a single lumen to remain heparin-free (arterial line or central venous line) during CICU admission, and drew UFH for monitoring lab values from this port. However, in the absence of a dedicated line, venous puncture was considered the next method of sampling.

Therapeutic range for aPTT was defined as 60 to 80 seconds, whereas therapeutic range for anti-Xa was defined as 0.3 to $0.7 \mathrm{IU} / \mathrm{mL}$. Paired values of aPTT and anti-Xa were considered concordant if both were within the therapeutic range, both were above therapeutic range (supratherapeutic), or both were below therapeutic range (subtherapeutic), otherwise they were considered discordant.

\section{Exclusion Criteria}

Patients who were treated with UFH $<10 \mathrm{U} / \mathrm{kg} / \mathrm{h}$ without titration (eg, to maintain line patency) were excluded from analysis.

\section{Study End Points}

The primary outcome measure was a composite of major and clinically relevant nonmajor bleeding events during treatment with therapeutic UFH. To identify and adjudicate these events, we collected the data via a daily prospective review of the records of all patients in the CICU treated with therapeutic UFH. Clarifications of key end points (eg, the indication for a blood transfusion) were answered by discussion with the treating medical team, including the bedside nurse, front-line provider, or attending 


\begin{tabular}{|c|c|c|c|c|c|c|}
\hline anti-Xa & $<60$ & $60-85$ & $86-100$ & $101-124$ & $125-150$ & $>150$ \\
\hline$<0.2$ & $\begin{array}{l}\text { Increase by } 20 \% \\
\text { (4 hours) }\end{array}$ & $\begin{array}{l}\text { Increase by } 10 \% \\
\text { (4 hours) }\end{array}$ & $\begin{array}{l}\text { No change } \\
\text { (12 hours) }\end{array}$ & $\begin{array}{c}\text { Decrease by } 10 \% \\
\text { (4 hours) }\end{array}$ & $\begin{array}{c}\text { Decrease by } 20 \% \\
\text { (4 hours) }\end{array}$ & $\begin{array}{c}\text { Hold for } 1 \text { hour } \\
\text { then decrease by } 25 \% \\
\text { (4 hours) }\end{array}$ \\
\hline $0.21-0.34$ & $\begin{array}{l}\text { Increase by } 10 \% \\
\text { (4 hours) }\end{array}$ & $\begin{array}{l}\text { No change } \\
\text { (12 hours) }\end{array}$ & $\begin{array}{l}\text { No change } \\
\text { (12 hours) }\end{array}$ & $\begin{array}{c}\text { Decrease by } 10 \% \\
\text { (4 hours) }\end{array}$ & $\begin{array}{c}\text { Decrease by } 20 \% \\
\text { (4 hours) }\end{array}$ & $\begin{array}{c}\text { Hold for } 1 \text { hour } \\
\text { then decrease by } 25 \% \\
\text { (4 hours) }\end{array}$ \\
\hline $0.35-0.7$ & $\begin{array}{l}\text { No change } \\
\text { (12 hours) }\end{array}$ & $\begin{array}{l}\text { No change } \\
\text { (12 hours) }\end{array}$ & $\begin{array}{l}\text { No change } \\
\text { (12 hours) }\end{array}$ & $\begin{array}{c}\text { Decrease by } 10 \% \\
\text { ( } 4 \text { hours) }\end{array}$ & $\begin{array}{c}\text { Decrease by } 20 \% \\
\text { (4 hours) }\end{array}$ & $\begin{array}{c}\text { Hold for } 1 \text { hour } \\
\text { then decrease by } 25 \% \\
\text { (4 hours) }\end{array}$ \\
\hline $0.71-0.8$ & $\begin{array}{c}\text { Decrease by } 10 \% \\
\text { (4 hours) }\end{array}$ & $\begin{array}{c}\text { Decrease by } 10 \% \\
\text { (4 hours) }\end{array}$ & $\begin{array}{c}\text { Decrease by } 10 \% \\
\text { ( } 4 \text { hours) }\end{array}$ & $\begin{array}{c}\text { Decrease by } 10 \% \\
\text { (4 hours) }\end{array}$ & $\begin{array}{c}\text { Decrease by } 20 \% \\
\text { (4 hours) }\end{array}$ & $\begin{array}{c}\text { Hold for } 1 \text { hour } \\
\text { then decrease by } 25 \% \\
\text { (4 hours) }\end{array}$ \\
\hline $0.81-0.9$ & $\begin{array}{c}\text { Decrease by } 20 \% \\
\text { (4 hours) }\end{array}$ & $\begin{array}{c}\text { Decrease by } 20 \% \\
\text { (4 hours) }\end{array}$ & $\begin{array}{c}\text { Decrease by } 20 \% \\
\text { ( } 4 \text { hours) }\end{array}$ & $\begin{array}{c}\text { Decrease by } 20 \% \\
\text { (4 hours) }\end{array}$ & $\begin{array}{c}\text { Decrease by } 20 \% \\
\text { (4 hours) }\end{array}$ & $\begin{array}{c}\text { Hold for } 1 \text { hour } \\
\text { then decrease by } 25 \% \\
\text { ( } 4 \text { hours) }\end{array}$ \\
\hline $0.91-1$ & \begin{tabular}{|c|} 
Hold for 1 hour \\
then decrease by \\
$25 \%$ \\
(4 hours) \\
\end{tabular} & \begin{tabular}{|c|} 
Hold for 1 hour \\
then decrease by \\
$25 \%$ \\
(4 hours) \\
\end{tabular} & $\begin{array}{c}\text { Hold for } 1 \text { hour } \\
\text { then decrease by } \\
25 \% \\
\text { (4 hours) } \\
\end{array}$ & \begin{tabular}{|c|} 
Hold for 1 hour \\
then decrease by \\
$25 \%$ \\
(4 hours) \\
\end{tabular} & $\begin{array}{c}\text { Hold for } 1 \text { hour } \\
\text { then decrease by } \\
25 \% \\
\text { (4 hours) } \\
\end{array}$ & $\begin{array}{l}\text { Hold for } 1 \text { hour } \\
\text { then decrease by } 25 \% \\
\text { (4 hours) }\end{array}$ \\
\hline$>1$ & \begin{tabular}{|c|}
$\begin{array}{c}\text { Hold for } 1 \text { hour } \\
\text { then recheck } \\
\text { before reinitiation }\end{array}$ \\
\end{tabular} & \begin{tabular}{|c|}
$\begin{array}{c}\text { Hold for } 1 \text { hour } \\
\text { then recheck } \\
\text { before reinitiation }\end{array}$ \\
\end{tabular} & $\begin{array}{c}\text { Hold for } 1 \text { hour } \\
\text { then recheck } \\
\text { before reinitiation }\end{array}$ & $\begin{array}{c}\begin{array}{c}\text { Hold for } 1 \text { hour } \\
\text { then recheck } \\
\text { before reinitiation }\end{array} \\
\end{array}$ & $\begin{array}{c}\begin{array}{c}\text { Hold for } 1 \text { hour } \\
\text { then recheck } \\
\text { before reinitiation }\end{array} \\
\end{array}$ & $\begin{array}{l}\text { Hold for } 1 \text { hour then } \\
\text { recheck before } \\
\text { reinitiation }\end{array}$ \\
\hline
\end{tabular}

FIGURE 1. The anticoagulation protocol for surgical patients at our institution. anti-Xa, Anti-factor Xa activity; aPTT, activated plasma thromboplastin time; PTT, partial thromboplastin time.

intensive care unit physician. Bleeding events were classified as major, clinically relevant nonmajor, or minor according to previously established definitions. ${ }^{13}$ Major bleeding was defined as new-onset intracranial bleeding or a source of bleeding that necessitated surgical or transcatheter intervention (surgical or endoscopic exploration, thoracic drainage tube) combined with a blood product transfusion requirement. Clinically relevant nonmajor bleeding was defined as bleeding resulting in blood product transfusion or $>20 \%$ decrease in hematocrit prompting cessation of anticoagulation. Minor bleeding included documented source of bleeding (endotracheal tube, nasogastric tube, gastrointestinal) without need for transfusion or cessation of UFH.

Thrombosis encompassed major symptomatic clinical findings such as shunt thrombosis, stroke, and peripheral arterial occlusions confirmed using imaging, as well as asymptomatic thrombosis identified using imaging. Severity of thrombosis was not classified, but rather recorded as a dichotomous end point (yes or no). All bleeding and thrombotic events were reviewed by an adjudication committee that consisted of cardiovascular surgeon, intensive care physician, cardiologist, and hematologist.

\section{Data Collection}

All data on doses and dosing changes of UFH were downloaded each day from an electronic data warehouse. Only patients undergoing UFH administration with goal of achieving "therapeutic" levels (defined as heparin dosing above $>10 \mathrm{U} / \mathrm{kg} / \mathrm{h}$ ), all of whom received aPTT and/or anti-Xa monitoring, were included in the analysis. For patients receiving therapeutic UFH, only the days on which patients were receiving therapeutic UFH were included in the analysis, and days not receiving UFH were excluded from analysis. For each day ( 7 AM to $7 \mathrm{AM}$ ), the maximum aPTT with the corresponding anti-Xa for the preceding 24 hours were recorded.

\section{Statistical Methods}

Incidence rates for bleeding and its subcategories were calculated using the number of events and the total number of days receiving therapeutic heparin per patient. Poisson regression was used to compare incidence rates according to age group. The correlation between aPTT and anti-Xa was estimated using a generalized linear model with compound symmetry covariance structure. Generalized additive modeling was used in initial analysis to assess the shape of the covariate function for aPTT and anti-Xa versus the probability of bleeding. Logistic piecewise regression modeling with generalized estimating equations, with cut points informed by generalized additive modeling, was used for significance testing and estimation of odds ratios (ORs). The aPTT assay had an upper detectable limit of 200 seconds; values above the detectable limit were set to 201 for use in analysis. The anti-Xa assay had a lower detectable limit of 0.10 ; values below the detectable limit were set to 0.05 for use in analysis. A $P$ value of. 05 was considered statistically significant. Analyses were performed with SAS version 9.4 (SAS Institute Inc, Cary, NC) and R version 3.2.1 (R Foundation for Statistical Computing, Vienna, Austria).

\section{RESULTS}

A cohort of 202 patients was followed for a total of 1488 patient-days (PD) while receiving therapeutic UFH. The median age at surgery was 0.4 years (interquartile range [IQR], 0.1-2.3 years) and the median length of stay in the CICU was 10 days (IQR, 5.0-17 days). Patient characteristics are listed in Table 1. Fifty-four patients $(26.8 \%)$ were admitted to the CICU after aortic, mitral, pulmonary, or tricuspid valve replacement/repair whereas $19(9.4 \%)$ were admitted after stage 1 . Fontan was performed in $14(6.9 \%$; Table E1). The indications for anticoagulation included single-ventricle physiology in 43 patients $(21.3 \%)$, complex intracardiac baffles in 12 $(5.9 \%)$ patients, valve replacements in 13 patients $(6.4 \%)$, and others including history of recent or remote thrombosis in the remaining $(66.3 \%)$. Thrombosis occurred in 19 patients $(9.4 \%)$. The incidence of thrombosis was 1.68 events per $100 \mathrm{PD}$.

There were 104 PD with bleeding events in patients treated with therapeutic UFH: bleeding was classified as 
TABLE 1. Patient characteristics for those with heparin $>10 \mathrm{U} / \mathrm{kg} / \mathrm{d}$

\begin{tabular}{lc}
\hline \multicolumn{1}{c}{ Variable } & Value \\
\hline $\mathrm{N}$ & 202 \\
\hline Median age at surgery (IQR), y & $0.4(0.1-2.3)$ \\
\hline Median weight at surgery (IQR), kg & $5.8(3.4-11.7)$ \\
\hline Neonate (<28 d) & $54(26.7 \%)$ \\
\hline Infant (29 d to 1 y) & $74(36.6 \%)$ \\
Non-infant (>1 y) & $74(36.6 \%)$ \\
\hline Median length of stay (IQR), d & $10.0(5.0-17.0)$ \\
Median number of days on therapeutic heparin (IQR) & $5.0(3.0-9.0)$ \\
\hline RACHS category & \\
RACHS 0 & $15(7.4 \%)$ \\
RACHS 1 to 3 & $98(48.5 \%)$ \\
RACHS 4 to 6 & $37(18.3 \%)$ \\
RACHS 7 & $44(21.8 \%)$ \\
RACHS & $3.9 \pm 2.2$ \\
Median RACHS (IQR) & $3.0(3.0-6.0)$ \\
\hline Anticoagulation indication & \\
Single-ventricle physiology & $43(21.3 \%)$ \\
Valve replacements & $13(6.4 \%)$ \\
Complex intracardiac baffles & $12(5.9 \%)$ \\
Others (eg, history of thrombosis before surgery) & $134(66.3 \%)$ \\
\hline$I Q R$, Interquartile range; $R A C H S$, Risk Adjustment for Congenital Heart Surgery.
\end{tabular}

major during $4 \mathrm{PD}$, as clinically relevant nonmajor bleeding in $41 \mathrm{PD}$, and as minor in $59 \mathrm{PD}$. The location of bleeding included the thoracic cavity, atrial line-related bleeding, and airway (Table E2). These events occurred in a total of 62 patients $(30.4 \%)$, and 4 patients $(2.0 \%)$ had a major bleed. The composite of major or clinically relevant bleeding occurred in 29 patients $(14.2 \%)$. The overall incidence of bleeding was 6.99 events per 100 PD (0.27 major bleeds per $100 \mathrm{PD}$ and 2.76 clinically relevant bleeds per 100 PD). The combined incidence of major and clinically relevant bleeding was 3.02 events per 100 PD. The incidence of clinically relevant or major bleeding events was 1.67 events per $100 \mathrm{PD}$ for neonates, 1.84 events per $100 \mathrm{PD}$ for infants, and 7.45 events per $100 \mathrm{PD}$ for patients aged 1 year or older $(P=.030)$.

The median time from surgery to onset of bleeding was 3 days (IQR, 1-10 days) whereas the median time from the start of UFH to a bleeding event was 1 day (IQR, 0-7.25 days). The median dose of heparin for the entire cohort was $24 \mathrm{U} / \mathrm{kg} / \mathrm{h}$ (IQR, 20-32 U/kg/h). The median aPTT was 69.2 seconds (IQR, 54.5-90.2 seconds) whereas the median anti-Xa was $0.17 \mathrm{IU} / \mathrm{mL}$ (IQR, 0.01-0.3 IU/mL). Bleeding and nonbleeding groups did not appear to be significantly different in median age at surgery, complexity of the surgery, or in length of stay (Table 2).

The median aPTT was higher in the group with a clinically relevant or major bleeding event compared with those without bleeding (91 vs 70 seconds, respectively; $P=.005)$. There was no significant difference in the median anti-Xa in patients with bleeding compared with those without bleeding $(0.29$ vs $0.17 ; P=.13)$. There was no significant difference in the median length of stay in the intensive care unit in the bleeding cohort compared with the nonbleeding group (11.0 vs 10.0 days; $P=.37)$.

In this cohort of patients, 134 patients $(66.3 \%)$ received aspirin at some point during their CICU stay. Among 27

TABLE 2. Characteristics of the patients according to event

\begin{tabular}{|c|c|c|c|}
\hline Variable & Bleed (major and clinically relevant nonmajor events) & No bleed & $P$ value \\
\hline $\mathrm{N}$ & 27 & 175 & \\
\hline Median age at surgery (IQR), y & $0.3(0.04-2.9)$ & $0.4(0.05-2.0)$ & .83 \\
\hline Neonate $(<28 \mathrm{~d})$ & $7(25.9 \%)$ & $50(28.3 \%)$ & 1.00 \\
\hline Infant $(<1 \mathrm{y})$ & $15(55.6 \%)$ & $114(64.4 \%)$ & .40 \\
\hline Median length of stay (IQR), $d$ & $11.0(7.0-20.0)$ & $10.0(5.0-17.0)$ & .37 \\
\hline \multicolumn{4}{|l|}{ RACHS category } \\
\hline RACHS 0 & $2(7.7 \%)$ & $13(8.4 \%)$ & .10 \\
\hline RACHS 1 to 3 & $12(46.2 \%)$ & $85(50.9 \%)$ & \\
\hline RACHS 4 to 6 & $9(34.6 \%)$ & $26(15.6 \%)$ & \\
\hline RACHS 7 & $3(11.5 \%)$ & $41(25.2 \%)$ & \\
\hline Median RACHS (IQR) & $3.0(3.0-6.0)$ & $3.0(3.0-7.0)$ & .68 \\
\hline \multicolumn{4}{|l|}{ Laboratory results } \\
\hline Median aPTT per patient, sec & $\begin{array}{l}91(64-112) \\
\mathrm{n}=25\end{array}$ & $\begin{array}{c}70(50-88) \\
n=153\end{array}$ & .005 \\
\hline Median anti-Xa per patient, IU/mL & $\begin{array}{c}0.29(0.13-0.43) \\
\mathrm{n}=17\end{array}$ & $\begin{array}{c}0.17(0.01-0.33) \\
\mathrm{n}=107\end{array}$ & .13 \\
\hline
\end{tabular}

$I Q R$, Interquartile range; RACHS, Risk Adjustment for Congenital Heart Surgery; $a P T T$, activated plasma thromboplastin time; anti-Xa, anti-factor Xa activity. 

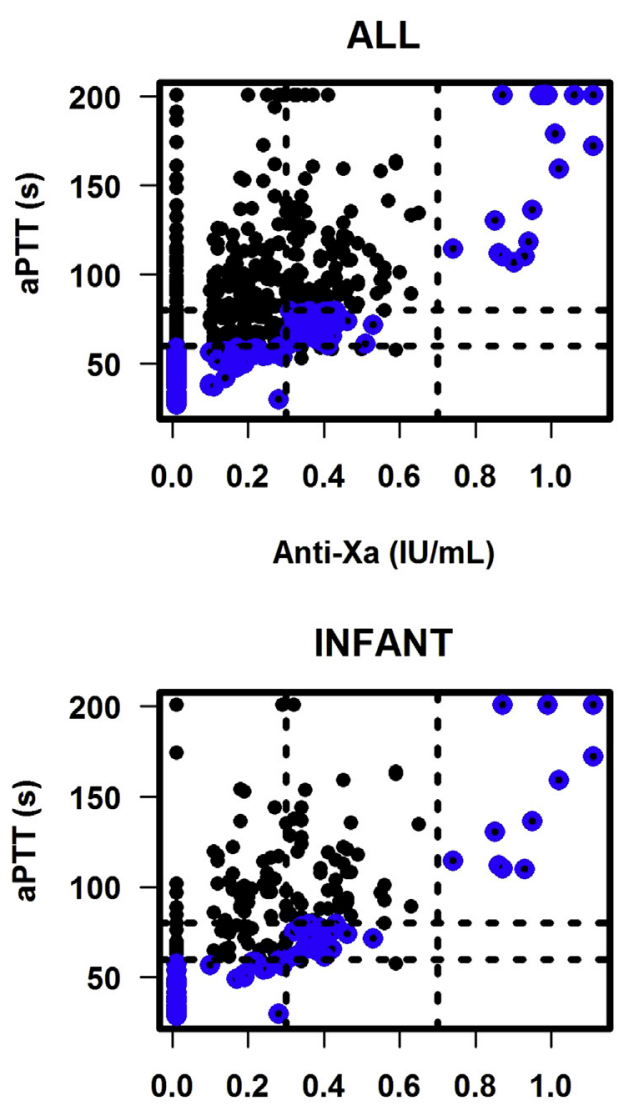

Anti-Xa (IU/mL)

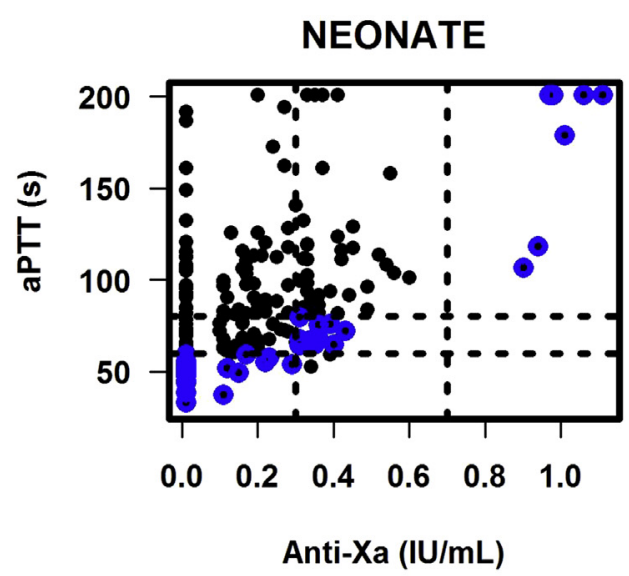

$>12$ MONTHS

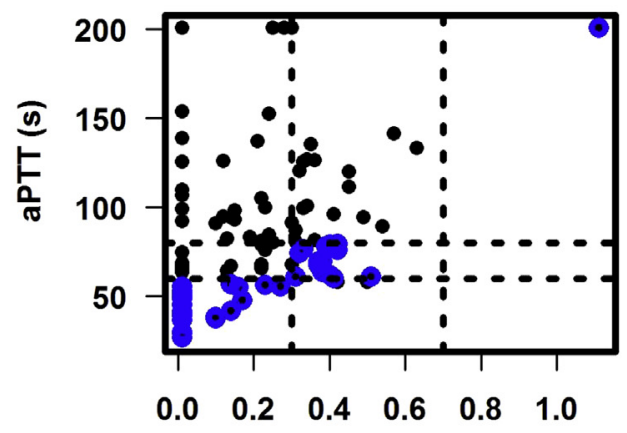

Anti-Xa (IU/mL)

FIGURE 2. Scatter plots of aPTT versus anti-Xa for the entire cohort (left upper panel; $R=0.58,95 \% \mathrm{CI}, 0.51-0.63$ ), neonates-age younger than 28 days (right upper panel), infant-age between 1 and 12 months (left lower panel), and older than 12 months (right lower panel). Blue color denotes concordance between aPTT and anti-Xa whereas black denotes discordance between aPTT and anti-Xa. aPTT, Activated plasma thromboplastin time; anti-Xa, anti-factor Xa activity.

patients who had clinically relevant or major bleeding, 6 were receiving aspirin 24 hours before the event (Table E3).

Among 1850 matched pairs of aPTT and anti-Xa used in the correlation analysis, $1343(72.6 \%)$ were found to be discordant. Most commonly, we found a supratherapeutic or therapeutic aPTT value with a simultaneously subtherapeutic anti-Xa (63.4\% of all matched pairs). Anti-Xa and aPTT were both supratherapeutic in only $2.5 \%$ of the pairs. Rarely was subtherapeutic or therapeutic aPTT associated with a supratherapeutic anti-Xa $(0.05 \%)$. The correlation between matched pairs of aPTT and anti-Xa adjusted for repeated measures was of moderate strength (Figure 2; $R=0.58 ; 95 \%$ confidence interval $[\mathrm{CI}], 0.51-0.63)$. The correlation was similar among neonates (age younger than 28 days) and other infants between 1 and 12 months of age $(R=0.56$ and $R=0.64$, respectively), but was somewhat lower in patients 1 year and older $(R=0.43 ; 95 \% \mathrm{CI}, 0.24-0.57)$.

A piecewise linear model best described the association between major or clinically relevant nonmajor bleeding and aPTT. Eight of the 45 major or clinically relevant nonmajor bleed-days occurred when aPTT was above 200 seconds in the preceding 24 hours. However, there was no association as long as aPTT was below 150 seconds (OR, 0.92; 95\% CI, 0.77-1.10; $P=.35$ ). When aPTT exceeded 150 seconds, the odds of major or clinically relevant nonmajor bleeding doubled with each 10-second increase (OR, 1.72; 95\% CI, 1.21-2.42; $P=.003$; Figure 3; Table 3). Anti-Xa did not correlate with major or clinically relevant nonmajor bleeding (OR, 1.11 per $0.1 \mathrm{IU} / \mathrm{mL}$ increase; $95 \% \mathrm{CI}, 0.89-1.29 ; P=.34$ ), and no significant thresholds were identified using piecewise regression modeling (Figure 4, Table 3). The median aPTT and anti-Xa in patients with thrombosis were 103.8 and 0.31 , respectively, compared with 85.3 and 0.22 in patients without thrombosis $(P=.39$ and .14$)$.

\section{DISCUSSION}

Anticoagulation with UFH is frequently indicated for prevention and/or treatment of thrombosis after pediatric 


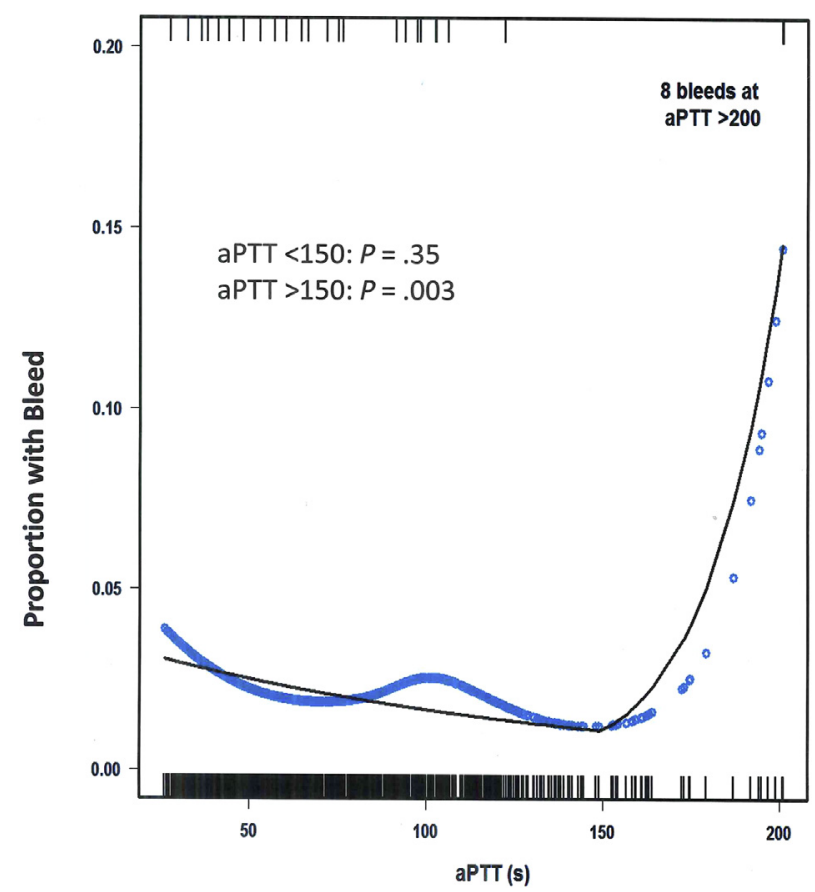

FIGURE 3. Estimated probability for clinically relevant or major bleeding versus aPTT. Blue line denotes flexible (nonparametric) fit. Black line denotes piecewise logistic regression model fit. aPTT, Activated plasma thromboplastin time.

cardiac surgery, but data-driven protocols for dose titration in this population have not been well established. This study shows that aPTT and anti-Xa are frequently discordant in pediatric patients after cardiac surgery who receive anticoagulation with UFH. It also shows that, in postoperative pediatric patients undergoing treatment with $\mathrm{UFH}$, the risk of major and clinically relevant nonmajor bleeding increases when aPTT is elevated beyond $150 \mathrm{sec}-$ onds (Video 1).

The most common complication of anticoagulation is bleeding, and the risk of significant bleeding is increased in patients with low body weight or congenital anomalies, and those undergoing complex surgeries. ${ }^{14}$ The incidence of bleeding reported in the literature varies across institutions. Kuhle et al in a prospective cohort study of 38 children requiring therapeutic doses of UFH reported the prevalence of major bleeding to be $24 \%$ for critically ill patients receiving UFH. ${ }^{15}$ Other studies have also shown the prevalence of bleeds in children receiving UFH to vary from $1.5 \%$ to $24 \% .^{2-4}$

A significant source of variability in the reported incidence of bleeding arises from the lack of standardized definition for bleeding. In this study we used the classification of bleeding that includes objective measures such as need for surgical re-exploration, transfusion, or discontinuation of anticoagulation (major or clinically relevant nonmajor bleeding). ${ }^{13}$ Other forms of bleeding including appearance of blood within endotracheal tube or nasogastric tube without need for medical or surgical intervention were recorded, and significantly alter the reported incidence of bleeding. Minor bleeding events are common, but of lower clinical significance and therefore not included in the analysis of correlation between laboratory values and bleeding.

The aPTT might be prolonged for reasons other than UFH effect, and this concern has led to the increased use of anti-Xa as the laboratory method of choice for titration of UFH. The activities of factors VIII, IX, XI, XII, prekallikrein, high molecularweight kininogen of the intrinsic pathway, and factors $\mathrm{X}, \mathrm{V}, \mathrm{II}$, and fibrinogen are reflected in the aPTT test. The test is also dependent on phospholipid and ionic calcium and an activator (eg, silica) of contact pathway-driven coagulation in vitro. It is also affected by vitamin $\mathrm{K}$ deficiency, liver disease, factor deficiencies, and hypofibrinogenemia. ${ }^{16}$

Previous studies have compared aPTT with anti-Xa in patients undergoing treatment with UFH. Mitchell et al reported little agreement between aPTT and anti-Xa in a prospective cohort study of 39 children receiving UFH for treatment of thrombosis or prophylaxis. Some of the indications for prophylaxis included Blalock-Taussig shunt, right ventricle to pulmonary artery conduit, and prosthetic valves. ${ }^{17} \mathrm{~A}$ retrospective, observational cohort study by Guervil et al compared aPTT with anti-Xa in the monitoring

TABLE 3. Clinically relevant/major bleed model results for aPTT and anti-Xa

\begin{tabular}{ccc}
\hline Predictor & Odds ratio $(\mathbf{9 5} \% \mathbf{C I})$ & $\boldsymbol{P}$ value \\
\hline Model 1: clinically relevant or major bleed (31 events, 178 patients, 1074 observations) & $0.92(0.77-1.10)$ & .35 \\
aPTT $\leq 150$ (per 10-second increase) & $1.72(1.21-1.42)$ & .003 \\
aPTT $>150$ (per 10-second increase) & $1.11(0.89-1.39)$ & \\
Model 2: clinically relevant or major bleed (9 events, 124 patients, 515 observations) & .34 \\
Anti-Xa (per 0.1 increase) & $1.23(0.64-2.33)$ & .54 \\
Model 3: clinically relevant or major bleed (9 events, 124 patients, 515 observations) & .90 \\
Anti-Xa $\leq 0.45$ (per 0.1 increase) & $1.03(0.62-1.71)$ & .90 \\
Anti-Xa $>0.45$ (per 0.1 increase)
\end{tabular}

$C I$, Confidence interval; $a P T T$, activated plasma thromboplastin time; anti-Xa, anti-factor Xa activity. 


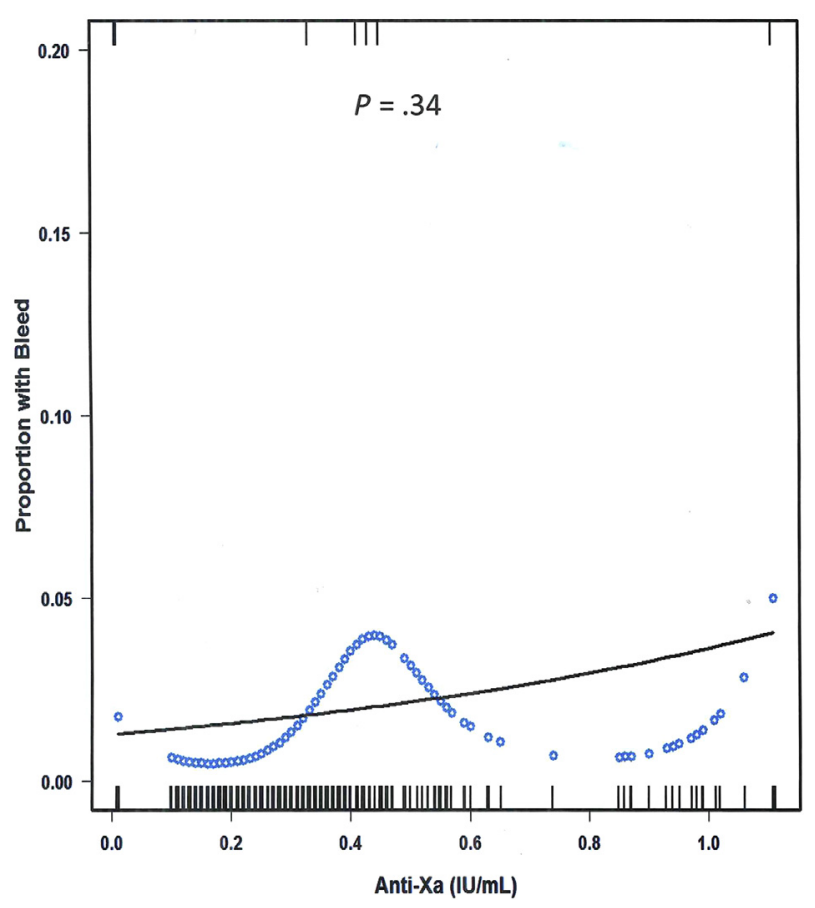

FIGURE 4. Estimated probability for clinically relevant or major bleeding versus anti-Xa. Blue line denotes flexible (nonparametric) fit. Black line denotes piecewise logistic regression model fit. anti-Xa, Anti-factor Xa activity.

of continuous infusion UFH $(n=100)$ and showed that anti$\mathrm{Xa}$ use achieves therapeutic anticoagulation faster and tends to maintain the value within the therapeutic range for longer. They also reported that with monitoring according to anti-Xa there were fewer repeated test adjustments to the dose of UFH. ${ }^{18}$

Although previous studies have shown the advantages of anti-Xa over aPTT in the titration of UFH, there are several reasons why those findings might not be applicable to pediatric populations after cardiac surgery. Anti-Xa is a biochemical assay that depends on the function of ATIII, which is generally lower in the first 6 months of life. Low anti-Xa might be associated with a significant discrepancy between biochemical assays and functional assays in young infants. However, in this study, the discrepancy between aPTT and anti-Xa was not correlated with ATIII levels. Furthermore, data supporting the use of anti-Xa are derived from patients who have not undergone recent cardiac surgery. The risk of bleeding with anticoagulation is likely to be significantly lower in unoperated patients compared with postoperative patients, particularly after cardiac surgical intervention. Although the risk of thrombosis is high in this population, the elevated risk of bleeding distinguishes these patients from those included in previous studies.

The study was unable to determine correlations between anti-Xa or aPTT and thrombosis outcomes because we did

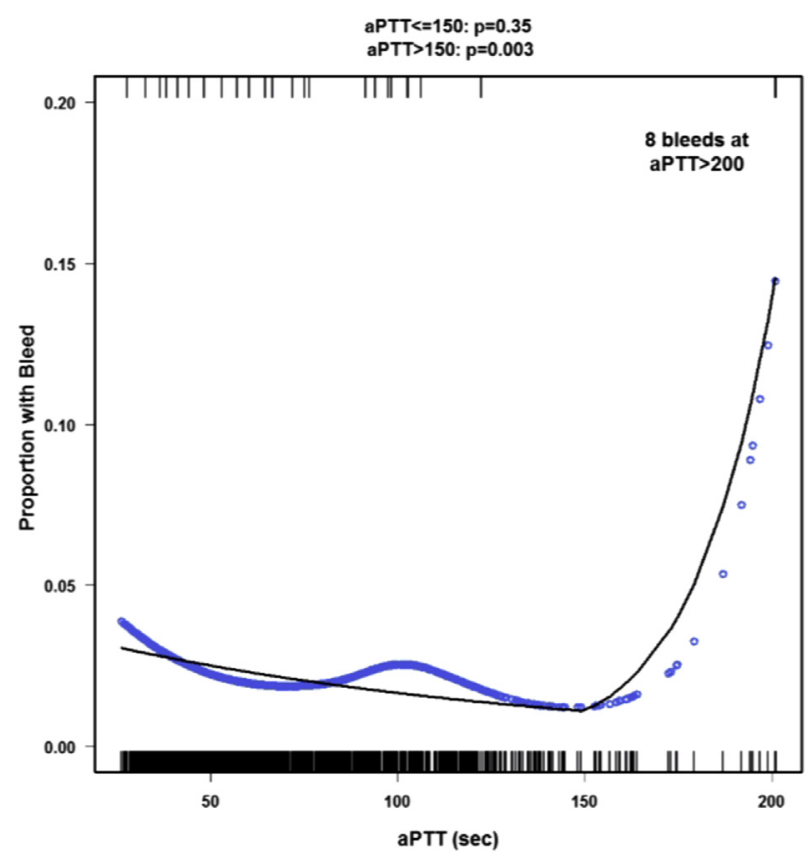

VIDEO 1. Clip of one of the authors explaining the importance and relevance of the work. aPTT, Activated plasma thromboplastin time. Video available at: https://www.jtcvs.org/article/S0022-5223(18)30892-4/fulltext.

not empirically screen for thrombosis. The risk of thrombosis is likely related to type of cardiac lesion and cardiac surgery, infection, inflammation, cardiopulmonary bypass, cumulative effect of UFH dosing strategy that includes not only the monitoring methodology, but also duration of therapy and concomitant antiplatelet agents used. Moreover, unlike bleeding events, which can be easily correlated with the anti-Xa or aPTT within the previous 24-hour period, thrombosis events are less likely to correlate with biomarkers within the previous 24-hour period. Furthermore, determination of the exact timing of a thrombosis event can be difficult. In patients with clinical or echocardiographic signs of thrombosis, it can be uncertain as to the exact timing of development of that thrombus. Thus, associating a thrombosis event with anti-Xa or aPTT on a particular day is not relevant and this study was not designed to evaluate thrombotic events. To determine the effect of an anticoagulation monitoring strategy on the incidence of thrombosis, a prospective randomized trial would be necessary.

There are several clinical implications of the study. The observation of increased risk of bleeding with aPTT levels $>150$ seconds suggests caution when increasing the UFH dose in postcardiotomy patients with elevated aPTT, even if the anti-Xa is subtherapeutic. Furthermore, the study supports the routine monitoring of aPTT in pediatric patients undergoing anticoagulation with UFH early after cardiac surgery and creating a ceiling for UFH dose titration 
on the basis of aPTT levels. However, because the study was not designed to show the relationship between thrombosis and anti-Xa or aPTT, a comprehensive recommendation regarding anticoagulation monitoring strategy could not be determined. Titration of UFH solely on the basis of aPTT cannot be recommended on the basis of these data and the results might not be applicable to noncardiac surgical pediatric populations.

The data from this study have been used to alter clinical practice at our institution. Before 2015, anti-Xa was predominantly used to titrate UFH in pediatric patients after cardiac surgery, with a target anti-Xa of 0.3 to $0.7 \mathrm{IU} / \mathrm{mL}$. The observation that the risk of bleeding increases with elevated aPTT levels prompted development of a UFH protocol that prevents increasing the dose of UFH when the aPTT exceeds 100 seconds. The protocol is outlined in Figure 1. All patients receiving UFH undergo laboratory monitoring with anti-Xa as well as aPTT. UFH is increased until the anti-Xa reaches the range of 0.3 to $0.7 \mathrm{IU} / \mathrm{mL}$. However, if the aPTT prolongs beyond 100 seconds, the UFH dose is decreased even if the anti-Xa is subtherapeutic. The threshold value of 100 seconds was chosen so as to provide sufficient reserve and ensure that aPTT levels do not approach the150-second value. However, the most appropriate ceiling aPTT level has not been established, and prospective trials are necessary to determine the effect of such a strategy on clinical outcomes of bleeding and thrombosis.

\section{Limitations}

One of the limitations to this study was that the anticoagulation monitoring strategy was not standardized throughout the study period. Other factors such as other anticoagulant medications, platelet count, fibrinogen level, intraoperative use factor VIIa (associated with ATIII depletion), disseminated intravascular coagulopathy screening, and heparin-induced thrombocytopenia screening were not collected in this study and as a result we could not control for these parameters. The correlation between anti-Xa and bleeding was determined on the basis of a small number of events and no patient had anti-Xa $>1.0 \mathrm{IU} / \mathrm{mL}$; therefore, there was limited statistical power to detect associations with supratherapeutic anti-Xa-a post hoc analysis indicates approximately $60 \%$ power to detect an OR of 2.0 per $1 \mathrm{SD}$ increase in anti-Xa. This was also a single-center study with relatively small sample size. Also, thrombosis is an important outcome of any anticoagulation strategy but our study design was unable to accurately determine the association between monitoring strategy and thrombosis.

\section{CONCLUSIONS}

The ideal method of monitoring anticoagulation with UFH in pediatric patients after cardiac surgery has not been established. There is a weak correlation between aPTT and anti-Xa, with monitoring frequently showing subtherapeutic anti-Xa in the presence of a therapeutic or supratherapeutic aPTT. In post-cardiac surgery heparinized patients, an aPTT level exceeding 150 seconds is associated with increased risk of bleeding, whereas there is no relationship between anti-Xa and bleeding. Future studies are necessary to determine the optimal method of UFH titration in these high-risk patients.

\section{Webcast}

You can watch a Webcast of this AATS meeting presentation by going to: https://aats.blob.core.windows.net/media/ 17AM/2017-05-01/RM306/05-01-17_Room306_1619_ Oladunjoye.mp4.

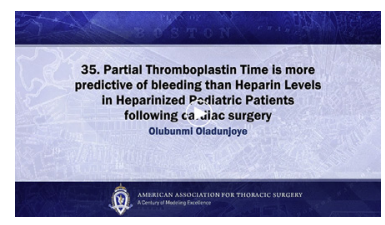

\section{Conflict of Interest Statement}

Authors have nothing to disclose with regard to commercial support.

\section{References}

1. Kuhle S, Eulmesekian P, Kavanagh B, Massicotte P, Vegh P, Lau A, et al. Lack of correlation between heparin dose and standard clinical monitoring tests in treatment with unfractionated heparin in critically ill children. Haematologica. 2007:92:554-7.

2. Andrew M, Marzinotto V, Massicotte P, Blanchette V, Ginsberg J, Brill-Edwards P, et al. Heparin therapy in pediatric patients: a prospective cohort study. Pediatr Res 1994;35:78-83.

3. Schechter T, Finkelstein Y, Ali M, Kahr WH, Williams S, Chan AK, et al. Unfractionated heparin dosing in young infants: clinical outcomes in a cohort monitored with anti-factor Xa levels. J Thromb Haemost. 2012;10:368-74.

4. Trucco M, Lehmann CU, Mollenkopf N, Streiff MB, Takemoto CM. Retrospective cohort study comparing activated partial thromboplastin time versus anti-factor Xa activity nomograms for therapeutic unfractionated heparin monitoring in pediatrics. J Thromb Haemost. 2015;13:788-94.

5. Emani S, Zurakowski D, Baird CW, Pigula FA, Trenor C, Emani SM. Hypercoagulability panel testing predicts thrombosis in neonates undergoing cardiac surgery. Am J Hematol. 2014;89:151-5.

6. Olson JD, Arkin CF, Brandt JT, Cunningham MT, Giles A, Koepke JA, et al. College of American Pathologists Conference XXXI on laboratory monitoring of anticoagulant therapy: laboratory monitoring of unfractionated heparin therapy. Arch Pathol Lab Med. 1998;122:782.

7. Vandiver JW, Vondracek TG. Antifactor Xa levels versus activated partial thromboplastin time for monitoring unfractionated heparin. Pharmacotherapy. 2012;32:546-58

8. Monagle P, Chan AK, Goldenberg NA, Ichord RN, Journeycake JM, Nowak-Göttl U, et al. Antithrombotic therapy in neonates and children antithrombotic therapy and prevention of thrombosis, 9th ed: American College of Chest Physicians evidence-based clinical practice guidelines. Chest. 2010;141:e737S-801S. Erratum in: Chest. 2014;146:1422.

9. Ignjatovic V, Furmedge J, Newall F, Chan A, Berry L, Fong C, et al. Age-related differences in heparin response. Thromb Res. 2006;118:741-5.

10. Price EA, Jin J, Nguyen HM, Krishnan G, Bowen R, Zehnder JL. Discordant aPTT and anti-Xa values and outcomes in hospitalized patients treated with intravenous unfractionated heparin. Ann Pharmacother. 2013;47: 151-8. 
11. Takemoto CM, Streiff MB, Shermock KM, Kraus PS, Chen J, Jani J, et al. Activated partial thromboplastin time and anti-Xa measurements in heparin monitoring. Am J Clin Pathol. 2013;139:450-6.

12. Fischbach FT, Marshall BD. Overview of Chemistry Studies. A Manual of Laboratory and Diagnostic Tests. Philadelphia: Lippincott Williams \& Wilkins; 2009.

13. Schulman S, Angerås U, Bergqvist D, Eriksson B, Lassen MR, Fisher W Definition of major bleeding in clinical investigations of antihemostatic medicinal products in surgical patients. J Thromb Haemost. 2010;8:202-4.

14. Brenner MK, Clarke S, Mahnke DK, Simpson P, Bercovitz RS, TomitaMitchell A, et al. Effect of 22q11.2 deletion on bleeding and transfusion utilization in children with congenital heart disease undergoing cardiac surgery. Pediatr Res. 2015;79:318-24.

15. Kuhle S, Eulmesekian P, Kavanagh B, Massicotte P, Vegh P, Mitchell LG. A clinically significant incidence of bleeding in critically ill children receiving therapeutic doses of unfractionated heparin: a prospective cohort study. Haematologica. 2007;92:244-7.

16. Khaja WA, Bilen O, Lukner RB, Edwards R, Teruya J. Evaluation of heparin assay for coagulation management in newborns undergoing ECMO. Am J Clin Pathol. 2010;134:950-4.

17. Mitchell LG, Kuhle S, Massicotte PM, Vegh P. Increased incidence of major bleeding in children receiving unfractionated heparin for clinical management: a prospective cohort study. Blood. 2004;104:1772.

18. Guervil DJ, Rosenberg AF, Winterstein AG, Harris NS, Johns TE, Zumberg MS. Activated partial thromboplastin time versus antifactor Xa heparin assay in monitoring unfractionated heparin by continuous intravenous infusion. Ann Pharmacother. 2011;45:861-8.

Key Words: anticoagulation, heparin, bleeding, thrombosis, congenital heart disease

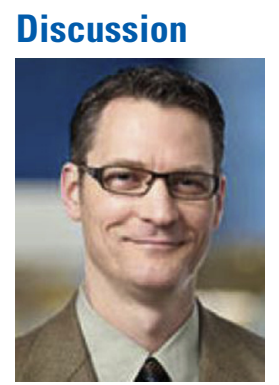

Dr David M. McMullan (Seattle, Wash). I would like to congratulate Dr Oladunjoye for an excellent presentation and I commend her for providing me with a copy of the manuscript well before the meeting. I enjoyed reading it thoroughly.

The challenge of optimal anticoagulation management is appreciated by all of us who care for young cardiac surgery patients, children on ECMO, and increasingly those who are managed on a ventricular assist device. Adult-based anticoagulation strategies might not be ideal for pediatric patients due to age-related variations in coagulation system factors, such as antithrombin III. Because no single marker of appropriate anticoagulation is universally applicable across patient populations, it is important to consider factors that might have contributed to patterns of age-related discordance highlighted in your study. So I was wondering if you can provide information about 3 of these.

Can you give us additional information about antithrombin III levels in your patients? Antithrombin III is known to be commonly lower in younger patients.

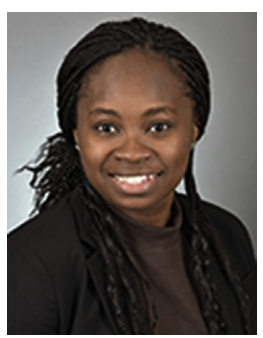

Dr Olubunmi O. Oladunjoye (Boston, Mass). Thank you for your questions. As we know, anti-Xa measures the heparin-antithrombin III complex, and when antithrombin III levels are low, then anti-Xa levels might also be low. We do not have the antithrombin III levels for our own patients, but in a cohort of patients who have been studied before now, we did find that aPTT levels varied with age and were particularly lower among the neonates. Also, studies in a cohort of patients also showed that antithrombin III alone might not account for all the discrepancies between aPTT and anti-Xa.

Dr McMullan. Additionally, did you measure prothrombin time, which might indicate factor deficiency as a cause of poor correlation between PTT and heparin levels?

Dr Oladunjoye. For our cohort of patients, we did not collect data on prothrombin time, but we are hoping to do so in the future.

Dr McMullan. I think this would be very helpful to try to understand the mechanism of the discordance.

How about aspirin therapy, can you comment on what portion of the patients were receiving aspirin and how that might have affected the risk of bleeding in this group?

Dr Oladunjoye. For our cohort of patients, we also did not put into consideration the other medications they were receiving, and aspirin would have definitely been one of the medications, which could also affect the coagulation of these patients, but we did not account for this.

Dr McMullan. I would suggest going back and looking at that, because I think that could significantly alter your outcomes.

And then finally, can you provide us some information about any change in outcomes you have noticed since you have implemented the new anticoagulation policy that you discussed in the manuscript?

Dr Oladunjoye. Our anticoagulation protocol that we started using a couple of months ago did titrate heparin on the basis of anti-Xa to achieve a therapeutic range of 0.3 to 0.7 , but then we capped it off when PTT exceeded 100 seconds. And since we instituted that, we have found that there was a reduction in the incidence of the composite of major bleeding or clinically relevant major bleeding.

Dr McMullan. I think that's very useful information and it will be very helpful for the communities to learn more about that, so I am looking forward to seeing your article in print. Thank you.

Dr Oladunjoye. Thank you. 
TABLE E1. Description of procedures

\begin{tabular}{lc}
\hline \multicolumn{1}{c}{ Primary procedure } & $\begin{array}{c}\text { Number of } \\
\text { patients (\%) }\end{array}$ \\
\hline Stage 1 procedure & $19(9.4)$ \\
\hline Bidirectional cavopulmonary anastomosis & $10(5.0)$ \\
\hline Fontan & $14(6.9)$ \\
\hline Arterial switch operation & $13(6.4)$ \\
\hline Tetralogy of Fallot repair & $17(8.4)$ \\
\hline Atrioventricular valve repair or replacement & $30(14.9)$ \\
\hline Aortic or pulmonary valve repair or replacement & $24(11.9)$ \\
\hline $\begin{array}{l}\text { Atrial or ventricular septal defect or complete } \\
\text { atrioventricular canal repair }\end{array}$ & $33(16.3)$ \\
\hline $\begin{array}{l}\text { Left ventricular obstructive lesion (eg, aortic } \\
\text { arch reconstruction) }\end{array}$ & $15(7.4)$ \\
\hline Pulmonary vein stenosis & $7(3.5)$ \\
\hline Other & $20(9.9)$ \\
\hline
\end{tabular}

TABLE E3. Other medications

\begin{tabular}{lc}
\hline Other medications & Total number of patients $(\%)$ \\
\hline Aspirin & $134(66.3)$ \\
Clopidogrel & $3(1.5)$ \\
Tirofiban & $2(1.0)$ \\
\hline
\end{tabular}

TABLE E2. Description of bleeding events

\begin{tabular}{ll}
\hline \multicolumn{1}{c}{ Bleeding events } & $\begin{array}{c}\text { Number of events } \\
\text { (number of patients) }\end{array}$ \\
\hline $\begin{array}{l}\text { Clinically relevant (nonmajor) bleeding events } \\
\text { Thoracic drainage tube or wound site bleeding } \\
\text { Line entry site bleeding (eg, previous } \\
\quad \text { cardiac catheterization site) }\end{array}$ & $21(17)$ \\
Airway bleeding & $11(6)$ \\
Gastrointestinal bleeding & $6(4)$ \\
Major bleeding events & $3(3)$ \\
$\quad$ Surgical site bleeding requiring surgical & \\
$\quad$ intervention (ie, thoracic exploration) & $1(1)$ \\
Line entry site bleeding requiring intervention & $1(1)$ \\
Intracranial hemorrhage & $2(2)$ \\
\hline
\end{tabular}

